\title{
Impact of patient-specific factors and spinopelvic alignment on the development of adjacent segment degeneration after short-segment lumbar fusion
}

\section{László Kiss}

National Center for Spinal Disorders

Zsolt Szövérfi

National Center for Spinal Disorders

Ferenc Bereczki

National Center for Spinal Disorders

Péter Endre Éltes

National Center for Spinal Disorders

Balázs Szöllösi

National Center for Spinal Disorders

Júlia Szita

National Center for Spinal Disorders

Áron Lazáry ( $\sim$ aron.lazary@bhc.hu )

National Center for Spinal Disorders https://orcid.org/0000-0002-0157-719X

Research article

Keywords: adjacent segment degeneration, MRI, risk factors, spinopelvic parameters, PROM, disc degeneration, disc bulge, major degenerative signs, short segment lumbar fusions, 5 year follow up

Posted Date: September 17th, 2021

DOI: https://doi.org/10.21203/rs.3.rs-898513/v1

License: (a) (1) This work is licensed under a Creative Commons Attribution 4.0 International License. Read Full License 


\section{Abstract}

Objectives: The main purpose of the study was to analyse the different demographical, morphological, and surgery-related parameters influencing the development or progress of degeneration in adjacent segments after routine, short-segment lumbar fusions.

Summary of Background data: Adjacent segment degeneration (ASD) considered as a major long-term complication after lumbar fusions. Possible risk factors are related to the patients' demographics, spinopelvic anatomy or preoperative lumbar intervertebral disc conditions. The current literature lacks of well-designed prospective studies focusing on the multidimensional nature of the condition.

Methods: A prospective cohort of 100 patients who underwent one- or two-level lumbar transforaminal interbody fusions due to lumbar degenerative pathology was conducted. Demographical, radiological findings (spinopelvic parameters, adjacent segmental radiological as well as magnetic resonance imaging (MRI) features) and long-term outcome data (5-year) were analysed to identify factors associated with ASD.

Results: ASD patients showed higher level of pain $(p=0.004)$ and disability $(p=0.020)$ at follow-up. In univariate analysis, older age, upper-level lumbar fusion $(p=0.007)$, lower L4-S1 lordosis $(p=0.039)$, PI-LL mismatch $(p=0.021)$, Pfirrmann grade III or higher disc degeneration $(p=0.002)$ and the presence of disc bulge/herniation were $(p=0.007)$ associated with ASD. Final result of multivariate analysis showed major degenerative sign (disc degeneration and/or disc bulge) as a risk factor (OR 3.85, Cl 1.43-10.37, p=0.006).

Conclusion: By examining the role of different patient- and procedure-specific factors, we found that preoperative major degenerative signs at the adjacent segment increase the risk of ASD causing significantly worse outcome after short-segment lumbar fusion. Adjacent disc conditions should be considered carefully during surgical planning.

\section{Background}

Spinal fusion has become the most frequent surgical method in treatment of degenerative spinal instability. $(1,2)$ Although lumbar fusion provides segmental stability, it can change the physiology and biomechanics of the adjacent segments by increasing motion and altering load in the adjacent facet joints and discs.(3) This can result in the deterioration of anatomical structures such as development of disc height reduction, disc bulging/herniation, spinal canal stenosis, spondylolisthesis and abnormal motion either in sagittal or in coronal plane.(4) The prevalence adjacent segment degeneration (ASD), the X-ray assessed morphological deterioration, development of clinical symptoms or the requirement of subsequent surgery vary in the literature between $4.8-100 \%$ and $0-30.3 \%$, respectively.(5-7) Morphological changes can be determined on standing X-rays using various parameters such as intervertebral disc height reduction, listhesis or change in segmental angle.(8-12) 
Numerous papers reported various factors associated with ASD such as age, female gender, body mass index (BMI), change in lumbar and segmental lordosis, high pelvic incidence, sagittal malalignment, preoperative disc degeneration and length of fusion respectively.(13-22) Some of these risk factors are related to the patients' demographics or spinopelvic anatomy. Possible role of preoperative lumbar degenerative signs and the features of the index surgery were also studied by some authors. $(23,24)$ Majority of studies focused on long lumbar-, thoracolumbar surgeries, and only few papers published the consequence of the most frequent, short-segment lumbar fusions. Despite the multifactorial nature of the condition, most studies have investigated only one or few risk factors, thus the literature lacks of welldesigned multiparametric studies.

In this prospective cohort study, the main purpose was to analyse the different demographical, surgeryrelated and morphological parameters in relation to the development or progress of degeneration in adjacent segments during a five-year long follow-up after routine, short-segment lumbar fusions.

\section{Materials And Methods}

Study cohort

One hundred consecutive adult patients were included into our prospective cohort study. Subjects were operated because of a lumbar degenerative (L1 to S1) condition between January and May 2015. Excluded pathologies were trauma, tumour, infection and congenital deformities. Index surgeries were one- or two-level open transforaminal lumbar interbody fusions (TLIF). Primary study endpoints were defined as the time of an adjacent segment degeneration related subsequent surgery (mean follow-up time in this subgroup was $2.69 \pm 2.04$ years) or 5-year follow-up (mean follow-up time was $5.01 \pm 0.45$ years in this subgroup). Indication for adjacent-level surgeries were analysed in details and presented in supplementary material (Supplementary Table 1).

The study was approved by the Scientific and Research Ethics Committee of the Medical Research Council.

Data collection

Demographical data were collected before the index operation. Surgery related parameters were the length of fusion (single-, or two levels), inclusion of the sacrum and the level of stabilisation. If the top instrumented vertebra were L4 or caudal, the surgery is considered as lower lumbar fusion all other cases considered as upper lumbar fusion. Radiological data were collected within 3 months before the index surgery (preoperative X-ray and MRI), within 5 days after the index surgery (postoperative X-ray) and at the follow-up (follow-up X-ray). Only for patients with subsequent surgery, lumbar MRI was performed before the primary endpoint to identify the source of pain and disability. Patient reported outcome questionnaires (PROM) were completed by subjects before the index surgery and at the endpoint. Validated versions of Oswestry Disability Index (ODI) was used to measure disability and Visual Analogue Scale (VAS) to assess pain (low back and leg pain). 
ASD was defined as a radiological change between postoperative and endpoint X-rays or the requirement of subsequent surgery because of degenerative pathology in the spinal segment adjacent to the index fusion. $(25,26)$ Radiological signs of ASD were determined on standing X-rays. Development of ASD was defined if at least one of the following was found: (I.) onset of segmental change in either kyphotic or lordotic equal or greater than $5^{\circ}$, (II.) decrease in disc height by 50 percent, (III.) anteroposterior translation equal or greater than $3 \mathrm{~mm} .(11,12)$

Radiological measurements

Radiological measurements were performed in Surgimap software (Surgimap ver. 2.3.2., New York, NY). Data were obtained from standing anteroposterior and lateral lumbar X-rays before the index surgery and at follow-ups. X-ray and MRI measurements were carried out based on previously published and validated methods. Spinopelvic (pelvic incidence (PI), sacral slope (SS), pelvic tilt (PT), lumbar lordosis (LL), L4-S1 lordosis) and segmental parameters (segmental lordosis in adjacent lumbar segment (sL), anterior and posterior disc height, antero-posterior translation) were measured. Antero-posterior translation in adjacent segment was measured as the distance between the posterior wall of the two-adjacent vertebral bodies, where the inferior vertebra is considered as fix point. Segmental lordosis in fusion site measured as the angle between the upper endplate of the most cranial vertebra and the lower endplate of the most caudal vertebra of the fusion. If the fusion involves the sacrum, the sacral plateau considered as the lower plane.

Detailed MRI analysis was performed to identify the signs of degeneration in adjacent intervertebral discs on preoperative MRIs. Five main phenotypes were studied: (1) Disc degeneration: MRI signal intensity, disc structure and distinctions among the nucleus pulposus and annulus fibrosus were classified according to five-grade Pfirrmann system.(27) (2) Disc bulge/herniation: Presence of disc material displacement was classified as bulgeing/protrusion or herniation in adjacent segments according to Fardon et al.(28) (3) Endplate damage: a trackable marker of disc degeneration process, classified based on its severity. The six-type-classification could distinguish between healthy (Type I), ageing (Type II-III) and degenerated (Type IV-VI) conditions.(29) (4) Annular fissure. Avulsions of annular fibres and fluid tracking thought that annulus fibrosus fissure presented as high signal intensity in T2-WI sequences.(30) (5) Modic change: classification of degenerative bone marrow changes were performed according to Modic et al.(31) In our statistical analysis all measured MRI parameters were dichotomized where Pfirrmann grade III or higher disc degeneration,(31) presence of disc bulge/protrusion or herniation considered as degenerative signs. These two phenotypes were merged together as major degenerative sign. Type II or higher endplate defect,(32) presence of annular fissure and any Modic type degeneration were also considered as degenerative conditions.

\section{Statistical analysis}

Differences in spinopelvic X-ray measurements between ASD and Non-ASD groups were assessed by applying Student's t-tests for parametric variables and Mann-Whitney U test for nonparametric variables. 
For categorical variables Chi-square or Fisher's exact tests were applied. Multiple logistic regression models were built to identify risk factors for ASD. Parameter selection were carried out based on parameters that were significantly different between groups. Stepwise backward conditional method was applied to extract the final model. Multicollinearity was evaluated by Pearson's rank correlation $(r>0.8)$.

Statistical analysis was performed using SPSS software (IBM Corp. released 2016. IBM SPSS Statistics, Version 24.0. Armonk, NY). P-values equal or less than 0.05 were considered as significant.

\section{Results}

A total of hundred patients were included in the cohort. Fifteen subjects were excluded from the final analysis due to incomplete dataset $(n=12)$ or surgical site infection $(n=3)$. Study subjects underwent single- $(n=62)$ or two-level $(n=23)$ transforaminal lumbar interbody fusions (TLIF). Based on ASD definitions 31 of the 85 patients ( 21 female and 10 male, $36.4 \%$ ) developed ASD until the primary endpoints, whereas the incidence of subsequent surgery was $17.6 \%$ at a follow-up ranging between 6 months to more than 4 years ( 15 patients).

\section{Demographics and surgery related factors}

Age was significantly higher in ASD group ( $47.1 \pm 11.6$ years vs $54.2 \pm 10.4$ years, $p=0.007)$. ASD patients showed higher preoperative pain $(6.8 \pm 2.2$ vs $7.8 \pm 1.7, p=0.048)$ and follow-up (FU) pain (4.6 \pm 2.9 vs. $6.5 \pm 2.5, p=0.004)$ and increased disability in ODI at follow-up ( $27.0 \pm 20.3$ vs. $38.3 \pm 21.8, p=0.020)$ compared to non-ASD groups. In regards of surgery related factors, upper-level lumbar fusion was more frequent in ASD group (6\% vs $26 \%$, Chi-square $=3.99, \mathrm{df}=1, p=0.007$ ) (Table 1 ).

\section{MRI phenotypes, intervertebral disc characteristics}

Pfirrmann grade III or higher disc degeneration at the adjacent level before the index surgery was more frequent in ASD group (24\% vs $51 \%$, Chi-square $=9.70, \mathrm{df}=1, p=0.002)$. The presence of disc bulge/herniation was three times higher in ASD patients ( $11 \%$ vs $35 \%$, Chi-square $=7.31, \mathrm{df}=1, p=0.007$ ). Major degenerative signs were more common in ASD cases (30\% vs $64 \%$, Chi-square $=9.81, \mathrm{df}=1$, $p=0.002$ ) (Table 2).

In regards of cases with subsequent surgeries, MRI findings in the adjacent segments were the followings: all cases showed advanced disc degeneration (15 cases, 100\%), 7 cases developed moderate to severe spinal canal stenosis (7 cases, $46.6 \%), 9$ patients showed large disc protrusion (9 cases, 60\%) and 3 cases developed disc extrusion (3 cases, 20\%) (Supplementary Table 1).

\section{Spinopelvic parameters}


Preoperative L4-S1 lordosis was significantly lower in ASD group $\left(32.9^{\circ} \pm 8.8^{\circ}\right.$ vs $\left.29.0^{\circ} \pm 7.3^{\circ}, p=0.039\right)$. PILL mismatch was greater in ASD patients $\left(-2.3^{\circ} \pm 9.7^{\circ}\right.$ vs $\left.3.2^{\circ} \pm 11.5^{\circ}, p=0.021\right)$. PT was higher in ASD group, which proved a trend to significant difference $\left(14.4^{\circ} \pm 7.5^{\circ}\right.$ vs $\left.17.7^{\circ} \pm 7.9^{\circ}, p=0.056\right)$ (Table $\left.3 \mathrm{~A}\right)$. Postoperative spinopelvic parameters showed no significant differences between groups (Table $3 \mathrm{~B}$ ).

\section{Multiparametric model for ASD}

Parameters that were significantly different between the two groups were entered into the final multiple logistic regression model, demographics (age), surgery related factors (upper/lower lumbar fusion), radiological parameters (preoperative L4-S1 lordosis, preoperative PI-LL mismatch and preoperative PT) and preoperative MRI signs of major disc degeneration. After application of stepwise backward conditional method, major degenerative sign ( $\mathrm{OR}=3.85, \mathrm{Cl} 95 \%=1.43-10.37)$ remained significant in the final model $(p=0.006)$.

\section{Discussion}

We analysed different morphological, demographical and surgery-related factors possibly influencing the degeneration of the adjacent segments after short-segment lumbar fusions in a prospective cohort study. Multiple regression model was applied to identify the major risk factor(s) of ASD. We found that presence of major degenerative signs in the adjacent segment before the index fusion surgery almost four-fold increased the occurrence of ASD. The impact of preoperative disc degeneration in adjacent segments was previously discussed in different studies. $(21,33,34)$ In our study, Pfirrmann grade III + severe disc degeneration and presence of disc bulge/protrusion in adjacent segment was significantly higher in ASD group. Similar findings were published by Ma, Ghasemi and Kim et al.(13, 25, 33). More degenerated segments can be more vulnerable for the altered biomechanics resulting in the development of clinically significant ASD. Indication for adjacent-level surgeries were analysed in details (Supplementary Table 1). Most patients were suffered from MRI proved discogenic disturbances such as severe disc degeneration (15/15 cases, $100 \%)$, moderate to severe spinal canal stenosis due to large protrusion ( $9 / 15$ cases, $60 \%)$ or herniation (3/15 cases, $20 \%)$. In all cases, fusion extension procedure was performed involving the affected adjacent segment.

Demographic parameters play important role in the degeneration process of the spine. Aging is a reliable factor of disc degeneration, although being a slow process .(32) In our study ASD group was significantly older compared to the Non-ASD group, although it was not a predictor in the multiple regression model. The reason behind it, could be the length of the follow up.

The current literature is controversial about the impact of instrumentation length and level in ASD. $(24,35$, 36) Patients with upper-level lumbar fusions more frequently developed ASD. The reason behind it might be the difference in lumbar segmental range of motions (ROM). As Cook et al described, the ROM of L1L3 segments are less flexible and more rigid compared to lower segments.(37) The rigidity might limit 
segmental compensatory mechanisms in adjacent segments in upper lumbar fusions and might lead to disc disturbances.

Higher pelvic tilt could represent further recruitment of compensatory mechanisms like pelvic retroversion to maintain balance. Preoperative PT was higher in ASD patients, as a trend to significant difference. However, this mild pelvic retroversion might play role in increased pain and disability.(38) In the final model PT was not proved as a risk factor of ASD, which supports finding of the current literature.(24)

The lumbar lordosis and its distribution are main aspects in lumbar stabilization surgeries. Patientspecific optimal amount of lordosis should be constructed and distributed as 50 to 80 percent of the overall lordosis should be in L4-S1 segments as stated by Yilgor at al. (39) In our study, LL was not turned out an influencing factor is ASD. Nevertheless, preoperative L4-S1 lordosis was significantly lower in ASD group. Improper distribution of lordosis have a significant consequence on sagittal alignment and can influence the local biomechanics too.(39). According to our knowledge, this is the first paper considering the influence of L4-S1 lordosis in development of adjacent segment degeneration. In current study, only ASD patients showed moderate PI-LL mismatch preoperatively according to original classification by Schwab et al.(40) The moderate mismatch combined with mild increase in PT could be the reason of higher pain and disability preoperatively in ASD patients, as stated by Schwab et al.(41)

Our prospective cohort study with a cross sectional follow up at five years provides valuable information about the adjacent segments after short-segment lumbar fusions. Our analyses contain multidimensional measurements (X-ray, MRI, PROM), using several pre- and postoperative factors. However, the relatively low number of patients in subgroups could limit our analysis. The length of follow-up may be also a limitation however, our 5-year long period is clinically adequate. We used only lumbar spine X-rays in our study due to technological limitations. Application of only lumbar X-rays could make an impact on the analysis since, there is a lack of information about the thoracic and cervical curves, and even global sagittal balance. To validate our findings the study should be repeated in larger cohorts.

\section{Conclusion}

Despite the multitude of studies published, the causes of ASD are not understood completely. The role of spinopelvic parameters or other factors that influence, induce or trigger changes in the adjacent mobile segments is not clear. By examining the effect of these factors, we found that preoperative major degenerative signs increase the risk of ASD. Adjacent disc conditions should be carefully analysed during surgical planning; if major degenerative signs are present, the inclusion of the segment into the index fusion is considerable.

\section{Abbreviations}

Adjacent segment degeneration (ASD)

Magnetic resonance imaging (MRI) 
Body mass index (BMI)

Transforaminal lumbar interbody fusion (TLIF)

Patient reported outcome questionnaires (PROM)

Oswestry Disability Index (ODI)

Visual Analogue Scale (VAS)

Pelvic incidence $(\mathrm{Pl})$

Sacral slope (SS)

Pelvic tilt (PT)

Lumbar lordosis (LL)

Segmental lordosis in adjacent lumbar segment (sL)

Follow-up (FU)

Range of motions (ROM)

\section{Declarations}

Ethics: The study was approved by the National Institute of Pharmacy and Nutrition (Reference Number: OGYÉl/163-4/2019).

Availability of data and materials: The datasets used and/or analysed during the current study are available from the corresponding author on reasonable request

Funding: The project leading to the scientific results was supported by the Hungarian Scientific Research Fund grant Budapest, Hungary (Award Number: OTKA FK123884).

Competing interests: Authors declare that the research was conducted in the absence of any commercial or financial relationships that could be construed as a potential conflict of interest.

Authors' contributions: LK referred for gathering and analysing patient data. LK, BF, BS, EP took part in radiological measurements. Statistical analysis was made by LK, JS and AL. LK was the major contributor of writing the manuscript. ZS was performed language editing. All authors read and approved the final manuscript.

\section{References}


1. Tye EY, Alentado VJ, Mroz TE, Orr RD, Steinmetz MP. Comparison of Clinical and Radiographic Outcomes in Patients Receiving Single-Level Transforaminal Lumbar Interbody Fusion With Removal of Unilateral or Bilateral Facet Joints. Spine. 2016. szeptember;41(17):E1039-45.

2. Phillips FM, Slosar PJ, Youssef JA, Andersson G, Papatheofanis F. Lumbar Spine Fusion for Chronic Low Back Pain Due to Degenerative Disc Disease: A Systematic Review. Spine. 2013. április;38(7):E409-22.

3. Lee C, Langrana NA. Lumbosacral spinal fusion. A biomechanical study. Spine (Phila Pa 1976). 1984. szeptember;574-81.

4. Virk SS, Niedermeier S, Yu E, Khan SN. Adjacent segment disease. Orthopedics. 2014;37(8):547-55.

5. Trivedi NN, Wilson SM, Puchi LA, Lebl DR. Evidence-Based Analysis of Adjacent Segment Degeneration and Disease After LIF: A Narrative Review. Global Spine Journal. 2018. február;8(1):95-102.

6. Zhang C, Berven SH, Weber MH. Adjacent Segment Degeneration Versus Disease After Lumbar Spine Fusion for Degenerative Pathology. 2016;29(1):9.

7. Xia X-P, Chen H-L, Cheng H-B Prevalence of Adjacent Segment Degeneration After Spine Surgery: A Systematic Review and Meta-analysis. Spine. 2013. április;38(7):597-608.

8. Weiner DK, Distell B, Studenski S, Martinez S, Lomasney L, Bongiorni D. Does Radiographic Osteoarthritis Correlate with Flexibility of the Lumbar Spine? Journal of the American Geriatrics Society. 1994. március;42(3):257-63.

9. Matsuoka Y, Endo K, Suzuki H, Sawaji Y, Nishimura H, Takamatsu T. és mtsai. Postoperative Radiographic Early-Onset Adjacent Segment Degeneration after Single-Level L4-L5 Posterior Lumbar Interbody Fusion in Patients without Preoperative Severe Sagittal Spinal Imbalance. Asian Spine J. 2018;12(4):743-8. augusztus $31 ;($.

10. Matsumoto T, Okuda S, Maeno T, Yamashita T, Yamasaki R, Sugiura T. és mtsai. Spinopelvic sagittal imbalance as a risk factor for adjacent-segment disease after single-segment posterior lumbar interbody fusion. SPI. 2017. április;26(4):435-40.

11. Moreau P-E, Ferrero E, Riouallon G, Lenoir T, Guigui P. Radiologic adjacent segment degeneration 2 years after lumbar fusion for degenerative spondylolisthesis. Orthopaedics \& Traumatology: Surgery \& Research. 2016. október;102(6):759-63.

12. Imagama S, Kawakami N, Matsubara Y, Tsuji T, Ohara T, Katayama Y, és mtsai. Radiographic Adjacent Segment Degeneration at 5 Years After L4/5 Posterior Lumbar Interbody Fusion With Pedicle Screw Instrumentation: Evaluation by Computed Tomography and Annual Screening With Magnetic Resonance Imaging. Clinical Spine Surgery: A Spine Publication. 2016. november;29(9):E442-51.

13. Ma Z, Huang S, Sun J, Li F, Sun J, Pi G. Risk factors for upper adjacent segment degeneration after multi-level posterior lumbar spinal fusion surgery. J Orthop Surg Res. 2019. december;14(1):89.

14. Masevnin S, Ptashnikov D, Michaylov D, Meng H, Smekalenkov O, Zaborovskii N. Risk Factors for Adjacent Segment Disease Development after Lumbar Fusion. Asian Spine J. 2015;9(2):239. 
15. Ou C-Y, Lee T-C, Lee T-H, Huang Y-H. Impact of Body Mass Index on Adjacent Segment Disease After Lumbar Fusion for Degenerative Spine Diseasec. Neurosurgery. 2015. április 1.;76(4):396-402.

16. Phan K, Nazareth A, Hussain AK, Dmytriw AA, Nambiar M, Nguyen D. és mtsai. Relationship between sagittal balance and adjacent segment disease in surgical treatment of degenerative lumbar spine disease: meta-analysis and implications for choice of fusion technique. Eur Spine J. 2018. augusztus;27(8):1981-91.

17. Ramirez-Villaescusa J, López-Torres Hidalgo J, Martin-Benlloch A, Ruiz-Picazo D, Gomar-Sancho F. Risk factors related to adjacent segment degeneration: retrospective observational cohort study and survivorship analysis of adjacent unfused segments. Br J Neurosurg. 2019;33(1):17-24. január 2 ;(.

18. Rothenfluh DA, Mueller DA, Rothenfluh E, Min K. Pelvic incidence-lumbar lordosis mismatch predisposes to adjacent segment disease after lumbar spinal fusion. Eur Spine J. 2015. június;24(6):1251-8.

19. Senteler M, Weisse B, Rothenfluh DA, Farshad MT, Snedeker JG. Fusion angle affects intervertebral adjacent spinal segment joint forces-Model-based analysis of patient specific alignment: PREDICTED INTERVERTEBRAL JOINT FORCES AFTER FUSION. J Orthop Res. 2017. január;35(1):131-9.

20. Tian H, Wu A, Guo M, Zhang K, Chen C, Li X. és mtsai. Adequate Restoration of Disc Height and Segmental Lordosis by Lumbar Interbody Fusion Decreases Adjacent Segment Degeneration. World Neurosurgery. 2018. október;118:e856-64.

21. Tsuji T, Watanabe K, Hosogane N, Fujita N, Ishii K, Chiba K. és mtsai. Risk factors of radiological adjacent disc degeneration with lumbar interbody fusion for degenerative spondylolisthesis. Journal of Orthopaedic Science. 2016. március;21(2):133-7.

22. Yamasaki K, Hoshino M, Omori K, Igarashi H, Nemoto $Y$, Tsuruta T, és mtsai. Risk Factors of Adjacent Segment Disease After Transforaminal Inter-Body Fusion for Degenerative Lumbar Disease. Spine. 2017;42(2):E86-92. január 15 ;(.

23. Xia X-P, Chen H-L, Cheng H-B Prevalence of Adjacent Segment Degeneration After Spine Surgery: A Systematic Review and Meta-analysis. Spine. 2013. április;38(7):597-608.

24. Wang T, Ding W. Risk factors for adjacent segment degeneration after posterior lumbar fusion surgery in treatment for degenerative lumbar disorders: a meta-analysis. J Orthop Surg Res. 2020. december;15(1):582.

25. Ghasemi AA. Adjacent segment degeneration after posterior lumbar fusion: An analysis of possible risk factors. Clinical Neurology and Neurosurgery. 2016. április;143:15-8.

26. Maragkos GA, Atesok K, Papavassiliou E. Prognostic Factors for Adjacent Segment Disease After L4L5 Lumbar Fusion. Neurosurgery. 2019. június 27.;nyz241.

27. Pfirrmann CWA, Metzdorf A, Zanetti M, Hodler J, Boos N. Magnetic Resonance Classification of Lumbar Intervertebral Disc Degeneration: Spine. 2001. szeptember;26(17):1873-8.

28. Fardon DF, Williams AL, Dohring EJ, Murtagh FR, Gabriel Rothman SL, Sze GK. Lumbar disc nomenclature: version 2.0. The Spine Journal. 2014. november;14(11):2525-45. 
29. Rajasekaran S, Venkatadass K, Naresh Babu J, Ganesh K, Shetty AP. Pharmacological enhancement of disc diffusion and differentiation of healthy, ageing and degenerated discs: Results from in-vivo serial post-contrast MRI studies in 365 human lumbar discs. Eur Spine J. 2008. május;17(5):626-43.

30. Adams MA, Roughley PJ. What is Intervertebral Disc Degeneration, and What Causes It?: Spine. 2006. augusztus;31(18):2151-61.

31. Modic MT, Steinberg PM, Ross JS, Masaryk TJ, Carter JR. Degenerative disk disease: assessment of changes in vertebral body marrow with MR imaging. Radiology. 1988;166(1 Pt 1):193-9.

32. Kushchayev SV, Glushko T, Jarraya M, Schuleri KH, Preul MC, Brooks ML. és mtsai. ABCs of the degenerative spine. Insights Imaging. 2018. április;9(2):253-74.

33. Kim KH, Lee S-H, Shim CS, Lee DY, Park HS, Pan W-J, és mtsai. Adjacent Segment Disease After Interbody Fusion and Pedicle Screw Fixations for Isolated L4-L5 Spondylolisthesis: A Minimum Five-Year Follow-up. Spine. 2010. március;35(6):625-34.

34. Liang J, Dong Y, Zhao H. Risk factors for predicting symptomatic adjacent segment degeneration requiring surgery in patients after posterior lumbar fusion. J Orthop Surg Res. 2014. december;9(1):97.

35. Anandjiwala J, Seo J-Y, Ha K-Y, Oh I-S, Shin D-C. Adjacent segment degeneration after instrumented posterolateral lumbar fusion: a prospective cohort study with a minimum five-year follow-up. Eur Spine J. 2011. november;20(11):1951-60.

36. Kumar MN, Jacquot $F$, Hall $\mathrm{H}$. Long-term follow-up of functional outcomes and radiographic changes at adjacent levels following lumbar spine fusion for degenerative disc disease. Eur Spine J. 2001. augusztus;10(4):309-13.

37. Cook DJ, Yeager MS, Cheng BC. Range of Motion of the Intact Lumbar Segment: A Multivariate Study of 42 Lumbar Spines. Int J Spine Surg. 2015;9:5.

38. Le Huec JC, Thompson W, Mohsinaly Y, Barrey C, Faundez A. Sagittal balance of the spine. Eur Spine J. 2019. szeptember;28(9):1889-905.

39. Yilgor C, Sogunmez N, Boissiere L, Yavuz Y, Obeid I, Kleinstück F, és mtsai. Global Alignment and Proportion (GAP) Score: Development and Validation of a New Method of Analyzing Spinopelvic Alignment to Predict Mechanical Complications After Adult Spinal Deformity Surgery. The Journal of Bone and Joint Surgery. 2017. október 4.;99(19):1661-72.

40. Schwab F, Ungar B, Blondel B, Buchowski J, Coe J, Deinlein D, és mtsai. Scoliosis Research SocietySchwab Adult Spinal Deformity Classification: A Validation Study. Spine. 2012. május;37(12):107782.

41. Schwab FJ, Blondel B, Bess S, Hostin R, Shaffrey Cl, Smith JS. és mtsai. Radiographical Spinopelvic Parameters and Disability in the Setting of Adult Spinal Deformity: A Prospective Multicenter Analysis. Spine. 2013. június;38(13):E803-12.

\section{Tables}


Table 1 Demographic characteristics, and surgical details

\begin{tabular}{llll} 
Demographics & Non-ASD & ASD & p \\
& $\mathbf{n}=\mathbf{5 4}$ & $\mathrm{n}=\mathbf{3 1}$ & \\
\hline Age, years (mean $\pm S D)$ & $47.1 \pm 11.6$ & $54.2 \pm 10.4$ & $\mathbf{0 . 0 0 7}$ \\
\hline Gender (M/F) & $19 / 35$ & $10 / 21$ & 0.784 \\
\hline BMI, kg/m²(mean $\pm S D)$ & $27.3 \pm 5.1$ & $28.5 \pm 4.8$ & 0.264 \\
\hline Pain (preop) & $6.8 \pm 2.2$ & $7.8 \pm 1.7$ & $\mathbf{0 . 0 4 8}$ \\
\hline ODI (preop) & $44.4 \pm 18.1$ & $48.1 \pm 14.3$ & 0.326 \\
\hline Pain (FU) & $4.6 \pm 2.9$ & $6.5 \pm 2.5$ & $\mathbf{0 . 0 0 4}$ \\
\hline ODI (FU) & $27.0 \pm 20.3$ & $38.4 \pm 21.8$ & $\mathbf{0 . 0 2 0}$
\end{tabular}

\section{Surgical details}

\begin{tabular}{llll}
\hline Length of Fusion (one/two-level, \%) & $41 / 13(76 \% / 24 \%)$ & $\begin{array}{l}20 / 11 \\
(65 \% / 35 \%)\end{array}$ & 0.261 \\
\hline Upper/Lower lumbar fusion ${ }^{\#}$ (upper/lower, \%) & $3 / 51(6 \% / 94 \%)$ & $\begin{array}{l}8 / 23 \\
(26 \% / 74 \%)\end{array}$ & 0.007 \\
\hline Inclusion of sacrum (yes/no, \%) & $33 / 21(61 \% / 39 \%)$ & $\begin{array}{l}16 / 15 \\
(51 \% / 49 \%)\end{array}$ & 0.394
\end{tabular}

Table 2 Distribution of preoperative MRI phenotypes between the ASD and Non-ASD groups ( $p$-values in bold indicate significant difference)

\begin{tabular}{llll} 
MRI phenotype & $\begin{array}{c}\text { Non-ASD } \\
\mathbf{n = 5 4}\end{array}$ & $\begin{array}{c}\text { ASD } \\
\mathbf{n = 3 1}\end{array}$ & $\mathbf{p}$ \\
\hline Disc degeneration & $13(24 \%)$ & $16(51 \%)$ & $\mathbf{0 . 0 0 2}$ \\
\hline Disc bulge/herniation & $6(11 \%)$ & $11(35 \%)$ & $\mathbf{0 . 0 0 7}$ \\
\hline Endplate damage & $43(80 \%)$ & $26(84 \%)$ & 0.630 \\
\hline Annular fissure & $1(2 \%)$ & $1(3 \%)$ & 0.116 \\
\hline Modic change & $22(41 \%)$ & $18(58 \%)$ & 0.124 \\
\hline Major degenerative sign & $16(30 \%)$ & $20(64 \%)$ & $\mathbf{0 . 0 0 2}$
\end{tabular}


Table 3 Comparison of preoperative (A) and postoperative (B) spinopelvic parameters ( $p$-values in bold indicate significant difference between Non-ASD and ASD groups)

\section{A}

\begin{tabular}{llll} 
Preop X-ray & $\begin{array}{c}\text { Non-ASD } \\
\mathbf{n}=54\end{array}$ & $\begin{array}{l}\text { ASD } \\
\mathbf{n}=31\end{array}$ & \\
\hline Pelvic Incidence $\left(^{\circ}\right)$ & $52.9 \pm 11.6$ & $56.9 \pm 12.5$ & 0.141 \\
\hline Sacral Slope $\left(^{\circ}\right)$ & $38.2 \pm 8.9$ & $39.6 \pm 9.6$ & 0.493 \\
\hline Pelvic Tilt $\left(^{\circ}\right)$ & $14.4 \pm 7.5$ & $17.7 \pm 7.9$ & 0.056 \\
\hline Lumbar Lordosis $\left(^{\circ}\right)$ & $55.2 \pm 12.4$ & $53.7 \pm 13.0$ & 0.601 \\
\hline L4-S1 lordosis $\left(^{\circ}\right)$ & $32.9 \pm 8.8$ & $29.0 \pm 7.3$ & 0.039 \\
\hline Segmental Lordosis in Fusion site $\left(^{\circ}\right)$ & $12.8 \pm 7.2$ & $10.9 \pm 6.4$ & 0.215 \\
\hline Pl-LL mismatch & $-2.3 \pm 9.7$ & $3.2 \pm 11.5$ & $\mathbf{0 . 0 2 1}$
\end{tabular}

B

\begin{tabular}{|llll}
\hline Postop X-ray & $\begin{array}{l}\text { Non-ASD } \\
\mathrm{n}=\mathbf{5 4}\end{array}$ & $\begin{array}{l}\text { ASD } \\
\mathrm{n}=\mathbf{3 1}\end{array}$ & \\
\hline Pelvic Incidence $\left(^{\circ}\right)$ & $52.4 \pm 11.9$ & $56.7 \pm 12.4$ & 0.122 \\
\hline Sacral Slope $\left(^{\circ}\right)$ & $35.2 \pm 8.9$ & $38.1 \pm 8.6$ & 0.163 \\
\hline Pelvic Tilt $\left(^{\circ}\right)$ & $17.2 \pm 6.9$ & $18.9 \pm 7.8$ & 0.309 \\
\hline Lumbar Lordosis $\left(^{\circ}\right)$ & $48.2 \pm 12.6$ & $51.5 \pm 10.9$ & 0.218 \\
\hline L4-S1 lordosis $\left(^{\circ}\right)$ & $31.6 \pm 9.4$ & $28.3 \pm 9.2$ & 0.130 \\
\hline Segmental Lordosis in Fusion site $\left(^{\circ}\right)$ & $13.0 \pm 6.9$ & $13.7 \pm 6.4$ & 0.647 \\
\hline PI-LL mismatch & $4.3 \pm 9.3$ & $5.2 \pm 8.9$ & 0.657
\end{tabular}

\section{Supplementary Files}

This is a list of supplementary files associated with this preprint. Click to download.

- supplementarymaterialjosr.docx 